\title{
Design and Development of the Module to Control the Quadcopter using the Signs shown by Hands
}

\author{
Alex A. Ezhov ${ }^{1}$, Vjacheslav I. Voronov ${ }^{2}$ \\ Department of Intelligent Control Systems and Automation \\ Moscow Technology University of Communication and Informatics \\ Moscow, Russia \\ 1alekcey_ezh@mail.ru, ${ }^{2} \underline{\text { vorvi@mail.ru }}$
}

\begin{abstract}
With the development of the industrial Internet of things (IIoT) there is a huge number of tasks that require the use of intelligent methods of information processing. Unmanned aerial vehicles (UAVs) are a class of IIoT devices that require computer vision to solve piloting tasks and provide the necessary functionality. The article describes the development of a module to control the quadcopter using gestures depicted by hands. The solution of this problem is very important to expand the methods of control actions.
\end{abstract}

Key words: IIoT, tensorflow, quadcopter, robot, neural network.

\section{INTRODUCTION}

Currently, the task of creating intelligent machines (robots) is extremely relevant. Robots can perform quite complex work; they are widely used in the industrial Internet of things: in production, in the organization of warehouses, in military Affairs, in medicine. Robots may have a different design, size and level of intelligence.

At the Department of ISUA MTUCI project is being designed for contactless control IIoT with the help of computer vision systems [1-3].

The article describes the development of an automatic mobile robot from the class of unmanned aerial vehicles. Using computer vision technology and machine learning methods. quadcopter will receive and recognize commands in the form of signs, depicted by the hands of the user and perform certain actions.

\section{ANALYSIS}

When determining the design of the robot, it is required to classify it taking into account the task indicated in the introduction. It is necessary not only select the appropriate housing materials, engines and mechanisms, but also to determine the system of computer vision and technologies of big data processing and machine learning [4-6].

The robot is an automatic device created on the principle of a living organism. Acting on a pre-programmed program and receiving information about the outside world from the sensors, the robot independently carries out production and other operations, usually performed by man (or animals). In this case, the robot can, as well as have a connection with the operator (receive commands from him), and act autonomously.

The basis of the modern robot is a set of actuators and devices with drive systems that allow you to interact with the environment in the performance of a given task. Drive-a set of devices designed to drive machines and mechanisms.

The functionality of the robot, its versatility and compliance with the characteristics is determined primarily by the variety of actions that the robot can perform.

The list of operations that the robot is designed to perform varies, depending on the list of special, specialized and universal robots. Special robots are designed to perform one specific task. Specialized robots can perform several similar operations. Universal robots can perform various basic and auxiliary operations within their technical capabilities. The increase in the degree of versatility of the robot extends the scope of its possible applications, but at the same time inevitably accompanied by underutilization of these opportunities for each specific operation, as well as the rise in the cost of the robot. Optimal in this respect are special robots, but on the other hand it is extremely narrows their market, and, consequently, the volume of production.

Manipulation robot is an automatic machine (stationary or mobile), consisting of an executive device in the form of a manipulator with several degrees of mobility, and a software control device that serves to perform motor and control functions in the production process. Such work is performed in outdoor, overhead and gantry designs. The most widely used in machinebuilding and instrument-making industries.

A mobile robot is an automatic machine that has a moving chassis with automatically controlled drives.

Mobile robots can be wheeled, walking and tracked (there are also crawling, floating and flying mobile robotic systems) depending on the type and operating conditions [1].

Classification of robots according to the characteristics of their design. These indicators include:

- type of drive;

- carrying;

- the number of manipulators; 
- $\quad$ type and parameters of their working area;

- $\quad$ mobility and method of placement;

- $\quad$ intended use.

Drives that are used in manipulators and robot movement systems can be electric, hydraulic and pneumatic. Often they are used in combination.

The load capacity of the robot is the load capacity of its manipulators, and for the transport robot also its chassis.

The number of manipulators in robots in most cases is limited to one. However, depending on the purpose, there are robot designs without manipulators and with 2, 3 and rarely 4 manipulators.

The type and parameters of the working area of the manipulator determine the area of the surrounding space within which it can perform manipulations without moving, i.e. with a fixed base.

The mobility of the robot is determined by the presence or absence of the robot movement system. In the first case, robots are called mobile, and in the second stationary.

According to the method of placement of stationary and mobile robots are floor, suspended and embedded in other equipment.

The use of the robot for its intended purpose depends on the external conditions in which it must operate. There are normal performance, dustproof, heatproof, moisture-proof, explosionproof, etc.

Automatic classification of robots according to the method of control: 1) Software; 2) Adaptive; 3) Intellectual.

Software control device. Such devices operate according to a predetermined program, mainly designed to solve monotonous problems in a constant environment.

Adaptive control device. In such systems, the control is carried out on the basis of the received information about the current state of the environment and the robot itself, obtained in the process of control from sensor devices (solve typical problems, and adapt to the operating conditions based on the data obtained from the information system).

Intelligent control device. These systems use artificial intelligence techniques to adapt and perform other robot functions.

Control devices can be individual, part of each robot and group, managing multiple robots. Structurally, individual control devices are usually performed separately from the mechanical part of the robot, much less often in the General body. Mobile robots usually have a control device consisting of 2 parts-on-Board and included in the operator panel (or in addition to it).

The vast majority of robots have electronic control devices made on the microcontroller. However, there are also nonelectric control devices of robots, often implemented on Pneumatics and intended for use in special explosive and fire hazardous conditions at elevated temperatures.
Since the quadcopter or UAV is used for operation, we will consider its structure in more detail.

UAVs are divided into several classes by weight, in this paper, we consider the AIRCRAFT belonging to the class "mini", because it has a mass of not more than $4 \mathrm{~kg}$. It consists of body, engine, onboard control system (autopilot), ground control system (NSO) and aerial photography equipment.

The UAV body is made of lightweight but durable materials, such as carbon fiber or Kevlar, to protect cameras and sensors, and the wings are made of extruded polystyrene foam (EPP). This material is light enough and does not break when falling. Manufacturers are trying to make cheaper parts of the body to keep the UAV in working condition was less expensive.

The engine can be either petrol or electric. The gasoline engine has one main advantage: it provides a longer flight, but this engine is less reliable and more complex in design. The electric motor is easy to operate, simple in design and requires less maintenance.

Autopilot is the main control element of the UAV. It has a processor and many sensors that monitor the deviation of the UAV during the flight.

Ground control system (NSO) is a computer; it is installed software to track the flight, which communicates with the UAV. Most often, the task for the UAV is defined as a flight at specified coordinates or points. During the flight, the NSO displays the coordinates of the terrain, as well as the altitude of the UAV flight, so that the operator can redirect, make an emergency landing or adjust the flight.

A quadcopter, also called a helicopter, is a multi-engine helicopter that is lifted and propelled by four rotors. Quadcopters are classified as rotary-wing aircraft, as opposed to aircraft, because their rise is made by means of rotors (vertically oriented propellers).

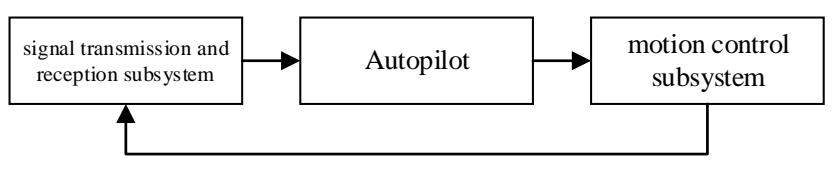

Fig. 1. Block diagram of the quadcopter

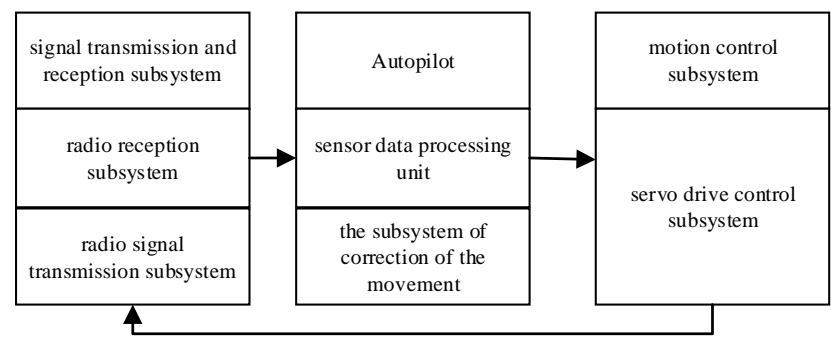

Fig. 2. Structural and functional scheme of the quadcopter

Quadrocopters typically use two pairs of identical fixed propellers; two of which operate clockwise $(\mathrm{CW})$ and two counterclockwise $(\mathrm{CCW})$. For more precise control and control of the quadcopter, an independent change in the speed of each 
rotor is used, as well as due to this, you can change the desired total thrust in a large range. The use of changing the speed of individual rotors helps to position the center of thrust in both transverse and longitudinal direction and change the torque or turning force.

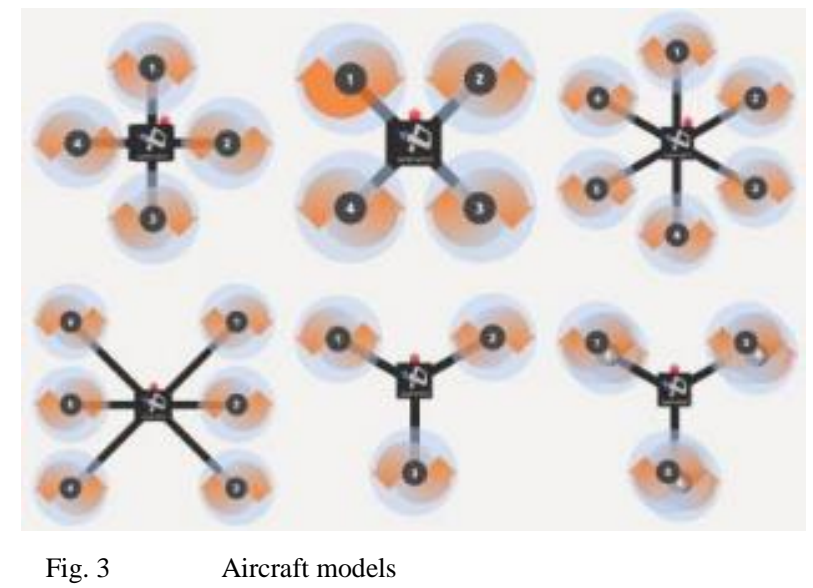

Remote control controller controls the quadcopter, by radio waves.

To communicate and respond to the requests of the copter control panel, the UAV is installed electronic systems:

* Flight controller-is an important component of the UAV, as it gives the user the ability to maneuver the device according to his wishes. First, the flight controller receives signals from the operator's transmitter. This allows commands and user instructions to reach the quadcopter. The flight controller is also useful for working together with sensors that are placed on Board for smooth flight. The controller has another function. A quadcopter is multirotor, which comes with four different engines. Each engine has a certain speed. Thus, the flight controller is able to calculate the speed of each of the four engines, and then sends a signal to the electronic speed controllers or ESC. This facilitates a smooth flight. The quadcopter flight controller can perform each of these functions mentioned above many times, resulting in efficient flight.

- An accelerometer is essentially a device that measures the linear acceleration of a quadcopter in a 3-axis system. This sensor gives an output that allows the user to understand the position of the drone. The simple fact that the accelerometer is able to detect and respond to gravity means that it remains stable in the air, ensuring a smooth flight. The correct way to install the accelerometer on the flight controller Board is to align the linear axis of the device with the primary axis of the UAV.

- A gyroscope (like an accelerometer) is useful for measuring the rate of angular change. However, you need to do some iteration to get the angle. The rotational axis of the sensor must coincide with the axis of the UAV.

- Inert-measuring unit (IMU) consists of both gyroscope and accelerometer. Some systems combine the use of a magnetometer and similar devices.

- Magnetometer is an electronic compass placed on the controller Board. This is especially necessary to align the direction of the drone compared to the earth's magnetic field.

- Barometer is a device for measuring pressure. The pressure sensor on the drone can give us the exact altitude value of the device from sea level. The most accurate altitude information is determined by the combination of the GPS pressure and altitude sensor.

- Distance sensor basically improves the height value set by the pressure sensor or barometer. The distance sensor can be ultrasonic, laser or LIDAR technology.

Quadcopters are different from conventional helicopters, which use rotors that dynamically change the height of their blades as they move around the rotor hub.

At first, quadcopters were considered as an alternative solution to some problems of vertical flight. Torque-dependent control problems (as well as efficiency problems arising from the tail rotor, which does not create a useful lift) can be eliminated by counter-rotating, and relatively short blades are much easier to manufacture and adjust.

\section{DESIGN}

\section{A. Objectives}

The Department of ISUA carries out a number of projects on the development of automatic control systems for objects of the Internet of things $[7 ; 8]$. One of the subtasks design and build a robot that must perform such actions:

- stay stable in the air and wait for the command from the user,

- find a specified object with the help of the built-in video camera and recognize what you see, taking into account this, perform any actions,

- broadcast over a wireless connection the camera image.

\section{B. General scheme of the architecture of the robot}

The General scheme of the robot architecture can be divided into 4 levels: mechanics, electronics, reactive control, tactical control, external control.

The lowest level is the body of the quadcopter. It is mounted on level 1 engine control system and sensors.

These devices are connected to the level 2 microcontroller, in the firmware of which there are simple rules of reactions to the sensor or camera readings, for example, turn to the left. This firmware also contains a list of commands to control the robot's movement (forward, turn, etc.).

The intelligent filling of the robot is contained at level 3, which houses a sufficiently productive minicomputer, to which the camera and the microcontroller of level 2 are connected. The minicomputer analyzes the image and sensor information received from the microcontroller, based on this information 
controls the movement. There is also a wireless device (wi-fi) and the corresponding software, which provides a communication channel with level 4 .

The highest level (number 4) is an external storage for the accumulation and analysis of large amounts of data and/or an operator that can adjust the behavior of the robot and receive information from it.

TABLE I. The layered architecture of robot

\begin{tabular}{|l|l|}
\hline $\begin{array}{l}\text { Level 4: } \\
\text { external } \\
\text { control }\end{array}$ & $\begin{array}{l}\text { - Accumulation of information, } \\
\text { - planning, } \\
\text { - general management, } \\
\bullet \text { operator interface }\end{array}$ \\
\hline $\begin{array}{l}\text { Level 3: } \\
\text { tactical } \\
\text { control }\end{array}$ & $\begin{array}{l}\text { - Communication channel and external control protocol, } \\
\text {-camera control software, }\end{array}$ \\
\hline $\begin{array}{l}\text { Level 2: } \\
\text { reactive } \\
\text { control }\end{array}$ & $\begin{array}{l}\text { - Simple reaction (stop, forward, right, left), } \\
\text { •motor control. }\end{array}$ \\
\hline $\begin{array}{l}\text { Level 1: } \\
\text { electronics }\end{array}$ & $\begin{array}{l}\bullet \text { Motor driver, } \\
\text {-simple sensors }\end{array}$ \\
\hline $\begin{array}{l}\text { Level 0: } \\
\text { mechanics }\end{array}$ & -Body \\
\hline
\end{tabular}

\section{The hardware}

Set of equipment operation and its layout may be different.

TABLE II.

Options kit component parts

\begin{tabular}{|l|l|l|}
\hline $\begin{array}{l}\text { Level 4: } \\
\text { external PC } \\
\text { control }\end{array}$ & PC & \\
\hline $\begin{array}{l}\text { Level 3: } \\
\text { tactical } \\
\text { control }\end{array}$ & $\begin{array}{l}\text { send sensor data } \\
\text { directly to the server } \\
\text { using a simple } \\
\text { minicomputer } \\
\text { communication } \\
\text { module }\end{array}$ & minicomputer \\
\hline $\begin{array}{l}\text { Level 2: } \\
\text { reactive } \\
\text { control }\end{array}$ & microcontroller & \\
\hline $\begin{array}{l}\text { Level 1: } \\
\text { electronics }\end{array}$ & sensors and motor driver & \\
\hline $\begin{array}{l}\text { Level 0: } \\
\text { mechanics }\end{array}$ & the body of the quadcopter & \\
\hline
\end{tabular}

Thediagram of the robot hardware is shown in fig. 4 .

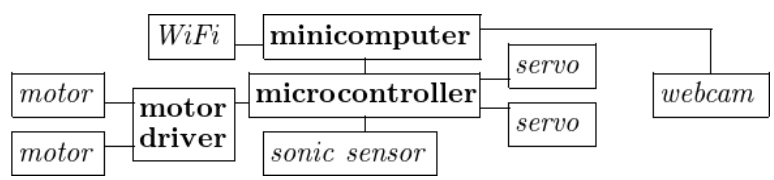

Fig. 4. Diagram of the robot's hardware

\section{IMPLEMENTATION}

To teach the robot to detect and recognize signs, an open library TensorFlow Object Detection API (Google) was used. It easily allows you to train your network from scratch. It was decided to use the so-called Deep Learning neural networks, because now they are the most advanced. Google provides many options for models. Each differs in speed and accuracy. SSD works fast, but can make mistakes with small objects. In addition, the fastest Faster RUN models work slowly but with greater accuracy. The TensorFlow Object Detection API provides a number of pre-trained models, shown in fig. 5 [10].

Fig. 5. Pre-trained Tensorflow models

\begin{tabular}{|c|c|c|c|}
\hline Model name & Speed (ms) & $\operatorname{cocomAP}\left[{ }^{\wedge} 1\right]$ & Outputs \\
\hline ssd_mobilenet_v1_coco & 30 & 21 & Boxes \\
\hline ssd_inception_v2_coco & 42 & 24 & Boxes \\
\hline faster_rcnn_inception_v2_coco & 58 & 28 & Boxes \\
\hline faster_rann_resnet50_coco & 89 & 30 & Boxes \\
\hline faster_rcnn_resnet50_lowproposals_coco & 64 & & Boxes \\
\hline ricn_resnet101_coco & 92 & 30 & Boxes \\
\hline faster_rcnn_resnet101_coco & 106 & 32 & Boxes \\
\hline faster_rcnn_resnet101_lowproposals_coco & 82 & & Boxes \\
\hline faster_rcnn_inception_resnet_v2_atrous_coco & 620 & 37 & Boxes \\
\hline faster_rcnn_inception_resnet_v2_atrous_lowproposals_coco & 241 & & Boxes \\
\hline faster_renn_nas & 1833 & 43 & Boxes \\
\hline faster_rcnn_nas_lowproposals_coco & 540 & & Boxes \\
\hline
\end{tabular}

The faster_run_resnet101_coco model is selected because it allows for maximum detection accuracy.

A dataset was created for training. Consisting of 300 photos. You want to increase the size of the data to increase the recognition accuracy. For the network to understand what it recognizes, you need to create a "label_map" file.txt, which contains the class description. Here is an example of such file:

item \{

id: 1

name: 'Hand'\}

Each photo needs to be annotated. This means that for each image you need to create an xml file that contains the name of the photo, its size and 4 coordinates, representing the location of the frame around the object, as well as the class of the desired object. Here is the file:

$<$ annotation>

$<$ filename $>182$.jpg </filename $>$

$<$ size $>$

<width $>1280</$ width $>$

$<$ height $>586</$ height $>$

$<$ depth $>3</$ depth $>$

$</$ size $>$

$<$ segmented $>0</$ segmented $>$

<object>

$<$ name $>$ Hand $</$ name $>$

$<$ bndbox $>$

$<x \min >581</ x \min >$

$<$ ymin $>106</ y \min >$

$<x \max >618</ x \max >$

$<y \max >142</ y \max >$

$</$ bndbox $>$

$<$ object $>$ 
In addition, the main thing is not to forget to divide the dataset into two samples of 70 and 30 percent. 70 for training and 30 for performance evaluation.

For more or less normal object detection, I recommend training the network for 200 thousand iterations. But for such a long process requires a very powerful iron. The developed network was trained on GPU GeForce $1050 \mathrm{Ti}$ for 25 thousand iterations. The detection accuracy reached $70 \%$. In the future, it is planned to use cloud computing, using, for example, Google VM.

Next, the network was tested on video downloaded from the Internet, respectively; it does not apply to the dataset. The result will result in Fig. 6.

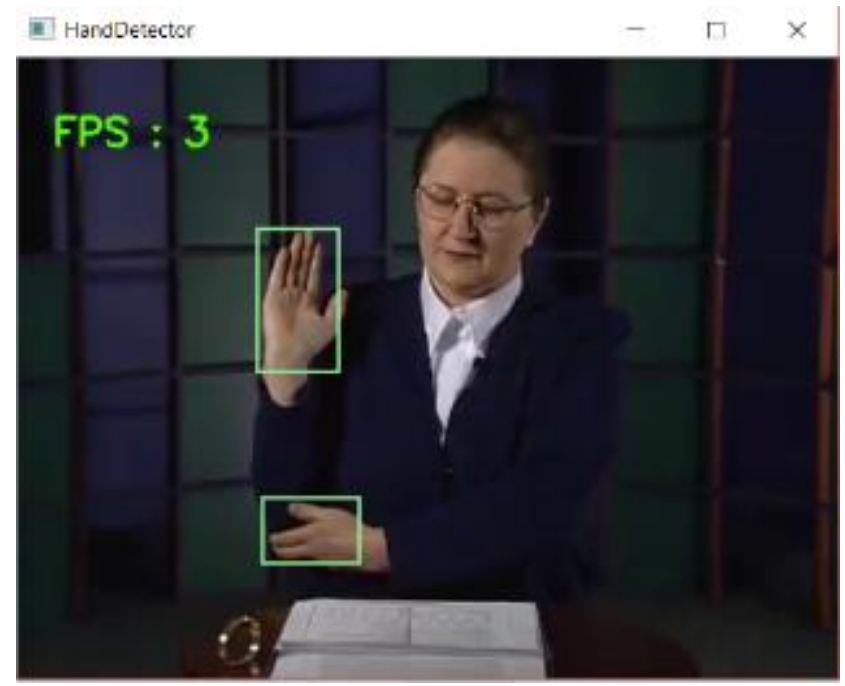

Fig. 6. The result of testing neural network

As you can see in the image, the network almost exactly finds both hands, but because I chose a slow model, the number of frames per second fell to 3 .

Now you need to decide how to control the quadcopter using a neural network. First, you can show the hands of certain signs that with the camera, the network will recognize. Each such sign will mean some simple action-right, left, up, down. Team of course can be build up over time. Secondly, you can just follow the movement of hands. For example, when flapping up, the quadcopter flies up, when flapping to the right-the quadcopter flies to the right, etc.

The first option has more commands to control, signs hands can come up with a lot. Compared with the second method, which takes into account only the direction of movement of the hands.

The second option is simple to implement, you only need to determine how the coordinates of the movement change and then it will be clear in which direction the hand is moving.

The first method requires training a second network that can classify the characters shown. This is as time-consuming a task as learning how to detect objects. As in the case of detection, the classification requires the creation of a dataset that contains at least 300 photos for each character. Some images are shown in fig. 7 [11].
Fig. 7. Sample images from the dataset

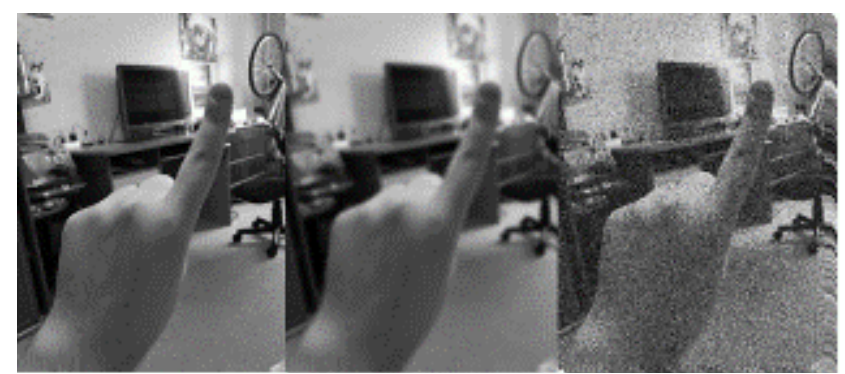

Due to the limited capacity in the creation of the dataset used technology to increase the amount of data by distortion. For example, blurring an image, adding noise, mirroring, and turning.

Now, the network classifies the signs with an accuracy of about $50 \%$. The work shows all the signs for training, because it will have to change and train the network again, so no sense to show it. To improve classification accuracy, you need to change the training dataset and increase its size.

\section{CONCLUSION}

In today's world, robots are getting a big leap in development. Many technologies make robots "smart" and help people in solving many problems. Therefore, the development of a mobile robot is a very relevant topic and will be such for a long time.

For the purposes of the course project required to design and develop a mobile robot. It was decided to use a model of a quadcopter, which would be controlled by the signs depicted by hands.

The structure and classification of robots are analyzed; the block diagram of the developed robot is presented. Its architecture and hardware are given.

Training of neural networks. Tested on a random video from the Internet, the detection accuracy of about $75 \%$.

The classification of signs requires considerable improvement, but the quadcopter can be controlled if you use the second method given in the work, in which you only need to know the direction of movement of the hands.

\section{$V I$.}

\section{REFERENCES}

[1] Михаеску С.В., Трунов А.С., Воронова Л.И. Анализ предметной области для разработки системы построения скелетной модели человека на основе массива опорных точек, получаемых совокупностью контроллеров KINECT // Международный студенческий научный вестник. 2015. № 3-4. C. 521-522. [Mihaesku S.V., Trunov A.S., Voronova L.I. Analysis of the subject area of system developing for building a human skeletal model based on an array of reference points obtained from a set of Kinect controllers // International Student Scientific Bulletin, 2015. N 3-4. P. 521-522].

[2] Клешнин Н.Г., Воронова Л.И. Применение нейронных сетей в подсистеме распознавания эмоций для проекта «сурдотелефон» // Телекоммуникации и информационные технологии. 2018. Т. 5. № 1. С. 126-130. [Kleshnin N.G., 
Voronova L.I. Neural networks application in emotion recognition module for "surdotelephone" project // Telecommunications and information technology. 2018. T. 5. № 1. P. 126-130].

[3] Воронов В.И., Воронова Л.И., Генчель К.В. Применение параллельных алгоритмов в нейронной сети для распознавания жестового языка // Актуальные проблемы инфотелекоммуникаций в науке и образовании (АПИНО 2018) VII Международная научно-техническая и научнометодическая конференция: Сб. науч. ст.: В 4 т. / Под ред. С.В. Бачевского. СПб., 2018. С. 207-212. [Voronov V.I., Voronova L.I., Genchel K.V. The use of parallel algorithms in the neural network to recognize the sign language // Actual problems of information and telecommunications in science and education (APINO 2018). VII International scientific tech. and scientific method. conf.: In 4 t. / Ed. S.V. Bachevsky. M., 2018. Р. 207-212].

[4] Воронова Л.И., Воронов В.И. Big Data. Методы и средства анализа: Учеб. пос. М., 2016. [Voronova K.I., Voronov V.I. Big Data. Methods and tools for analysis. Moscow, 2016].

[5] Усачев В.А., Воронов В.И. Компетенция «машинное обучение и большие данные» // Приоритетные направления развития науки и образования / Под общ. ред. Г.Ю. Гуляева. Пенза, 2017. C. 97-108. [Usachev V.A., Voronov V.I. The competence "Machine learning and Big Data" // Priorities for development of science and education / Ed. G.Yu. Gulayev. Pensa, 2017. P. 97$108]$.

[6] Горячев Д.В., Воронов В.И. Большие данные и машинное обучение // Технологии информационного общества: Матер.
XII Междунар. отраслевой науч.-техн. конф. М,, 2018. С. 327 328. [Goryachev D.V. Big Data and Machine Learning // Information Society Technologies: Proceedings of $12^{\text {th }}$ the international scientific-practical conference. Moscow, 2018. P. 327-328].

[7] Voronov V.I., Voronova L.I. Features of realization master's program "Automation of technological processes and manufactures" // International Journal of Applied and Fundamental Research. 2016. № 2. URL: www.science-sd.com/464-25196.

[8] Безумнов Д.Н., Воронова Л.И. О развитии и стандартизации технологии Интернета вещей // Технологии информационного общества: Матер. XII Междунар. отраслевой науч.-техн. конф. M., 2018. C. 293-294. [Bezumnov D.N., Voronova L.I. On the development and standardization of the Internet of Things technology // Information Society Technologies: Proceedings XII International. branch scientific.-tech. conf. Moscow, 2018. P. 293294].

[9] Blogs about robots. URL: http://enggmechanical.blogspot.com.

[10] Documentation TensorFlow. https://www.tensorflow.org/api_docs/.

[11] De Pontes Oliveira I., Peixoto Medeiros J.L., De Sousa V.F. A Data Augmentation Methodology to improve Age Estimation Using Convolutional Neural Networks. 2016 // 29th SIBGRAPI Conference on Graphics, Patterns and Images (SIBGRAPI). 2016. P. 88-95. 